\title{
KONTROVERZE U VEZI SA PRIMENOM MSFI ZA MALA I SREDNJA PRAVNA LICA U SRBIJI
}

\section{Milan Negovanović}

Privredni savetnik d.o.o. Beograd, Srbija
Korespondencija:

Milan Negovanović

e-mail:

milan.negovanovic@privsav.rs

\begin{abstract}
Apstrakt:
U ovom radu istraženi su izazovi i teškoće praktične primene Međunarodnog standarda finansijskog izveštavanja za mala i srednja pravna lica (MSFI za MSP) i preispitana je adekvatnost i celishodnost njihove primene u Republici Srbiji.

U radu su, putem poređenja sa kompletnim Međunarodnim standardima finansijskog izveštavanja, prikazana specifična obeležja MSFI za mala i srednja pravna lica; analizirane razlike između MSFI za MSP i računovodstvene direktive EU 2013/34/EU Evropskog parlamenta i Saveta od 26. juna 2013. godine; i prikazan stepen primene MSFI za mala i srednja pravna lica u Evropskoj uniji i drugim zemljama izvan EU.

Osim toga, ukazano je na to kako primena MSFI za MSP dovodi mala i srednja pravna lica u diskriminatoran položaj u odnosu na poslovne subjekte koji primenjuju kompletne MSFI, kao i na suvišno komplikovanje računovostvene regulative za sastavljanje finansijskih izveštaja. U radu su obrađena i druga sporna pitanja u vezi sa primenom MSFI za MSP koja posebno utiču na mala pravna lica, a koja su se ispoljila u dve godine primene ovih profesionalnih računovodstvenih standarda u Srbiji, tj. prilikom sastavljanja finansijskih izveštaja za 2014. i 2015. godinu.
\end{abstract}

Ključne reči:

mala i srednja pravna lica, Međunarodni standard finansijskog izveštavanja za mala i srednja pravna lica (MSFI za MSP), kompletni Međunarodni standardi finansijskog izveštavanja (MSFI), računovodstvena direktiva Evropske unije, računovodstvene politike.

UVOD

U skladu sa važećim Zakonom o računovodstvu iz jula 2013. godine, u Srbiji trenutno postoje tri vrste računovodstvene regulative:

- puni (kompletni) MSFI - koje primenjuju velika pravna lica, javna akcionarska društva i matična pravna lica koja imaju obavezu sastavljanja konsolidovanih finansijskih izveštaja;

- MSFI za MSP - koje primenjuju mala i srednja pravna lica i

- Pravilnik o načinu priznavanja, vrednovanja, prezentacije i obelodanjivanja pozicija u pojedinačnim finansijskim izveštajima mikro i drugih pravnih lica - koji primenjuju mikro pravna lica i preduzetnici koji poslovne knjige vode po sistemu dvojnog knjigovodstva. Ovaj Pravilnik je baziran na MSFI na MSP uz dodatna pojednostavljivanja za mikropravna lica.

Srednja pravna lica, umesto MSFI za MSP, mogu dobrovoljno da primenjuju pune MSFI uz obavezu da to rade na kontinuiranoj osnovi, a mikro pravna lica mogu dobrovoljno da primenjuju MSFI za MSP. Za razliku od njih, mala pravna lica (koja nisu javna akcionarska društva na berzi ili matično pravno lice koje ima obavezu sastavljanja konsolidovanih finansijskih izveštaja) ne mogu kao normativni okvir za sastavljanje finansijskih izveštaja dobrovoljno da izaberu pune MSFI, već moraju da primenjuju isključivo MSFI za MSP.

Međunarodni standard finansijskog izveštavanja za mala i srednja pravna lica je u Srbiji počeo da se primenjuje počev od sastavljanja finansijskih izveštaja za 2014. godinu. Izuzetno, mala pravna lica su završni račun za 2014. godinu mogla da sastavljaju po 
odredbama starog Pravilnika o načinu priznavanja i procenjivanja imovine, obaveza, prihoda i rashoda malih pravnih lica i preduzetnika (koji je donet 2006. godine) ukoliko su i dalje ostala razvrstana u mala pravna lica, ali samo za tu godinu.

Možemo sumirati da MSFI za MSP primenjuju sva mala pravna lica, srednja pravna lica (osim onih koja su se dobrovoljno opredelila da primenjuju kompletne MSFI) i mikro pravna lica (koja su se dobrovoljno opredelila za primenu MSFI za MSP).

Upravo zbog složenosti aktuelnog računovodstvenog sistema u Srbiji, ispoljenog kroz tri vrste računovodstvene regulative, i praktičnih teškoća u sprovođenju zahteva MSFI za MSP u dosadašnje dve godine njihove primene u Srbiji, u ovom radu želimo da ukažemo na glavne teškoće i potrebu da se postojeća zakonska rešenja preispitaju. To je neophodno, kako bi se zakonski okvir za poslovanje male privrede pojednostavio i da bi se eliminisale neusaglašenosti sa pravnim tekovinama EU, što je u interesu privrednih subjekata, korisnika finansijskih izveštaja, a u krajnjoj liniji i države.

\section{KLJUČNE KARAKTERISTIKE MSFI ZA MSP}

MSFI za MSP predstavljaju poseban računovodstveni standard za mala i srednja pravna lica koji je baziran na punim MSFI, a nastao je pojednostavljivanjem i skraćivanjem punih MSFI i prilagođavanjem izveštajnim potrebama manjih ekonomskih subjekata.

Pojednostavljenje se ogleda u činjenici da su iz MSFI za MSP izostavljene teme koje nisu bitne za izveštavanje malih i srednjih pravnih lica kao što su: zarada po akciji, periodično finansijsko izveštavanje, izveštavanje po segmentima, stalna sredstva namenjena prodaji i ugovori o osiguranju. Takođe, broj i sadržaj obaveznih obelodanjivanja u napomenama uz finansijske izveštaje znatno je manji u MSFI za MSP (oko 300), nego u potpunim MSFI (oko 3000).

Pored toga, MSFI za MSP ne daju određene alternativne računovodstvene politike i modele vrednovanja. Po njima nije moguća primena modela revalorizacije (procenjivanja po fer vrednosti) osnovnih sredstava i nematerijalnih ulaganja, izostavljene su opcije koje se odnose na klasifikaciju i vrednovanje hartija od vrednosti i drugih finansijskih instrumenata koji su raspoloživi za prodaju i koje se drže do dospeća. Uz to, njima nije data mogućnost izbora pri vrednovanju investicionih nekretnina i biolških sredstava po modelu nabavne ili fer vrednosti, već se njihovo vrednovanje obavezno vrši po procenjenoj fer vrednosti, osim ako je pouzdana procena po fer vrednosti prekomeran trošak ili napor za izveštajni subjekt itd.

Za razliku od punih MSFI koji obavezuju na kapitalizaciju troškova razvoja i rashoda kamata i drugih troškova pozajmljivanja (ukoliko se rashodi kamate i drugi troškovi pozajmljivanja mogu pripisati nabavci, izgradnji ili sticanju sredstva koja se osposobljavaju za upotrebu), MSFI za mala i srednja pravna lica zabranjuju takvu kapitalizaciju i propisuju da se svi rashodi kamata, troškovi pozajmljivanja i ulaganja u razvoj moraju priznati kao rashod perioda u kojem nastanu ${ }^{1}$.

\section{PRIMENA MSFI ZA MSP U SVETU}

U nastavku sledi spisak zemalja koje su usvojile MSFI za MSP prema zvaničnim podacima Odbora za MRS, odnosno IFRS fondacije.

Zemlje koje zahtevaju ili dozvoljavaju primenu MSFI za MSP Zvanični podaci IFRS fondacije iz avgusta 2016. godine

\begin{tabular}{lc}
\hline & $\begin{array}{c}\text { Broj } \\
\text { jurisdikcija }\end{array}$ \\
\hline EVROPA & \\
\hline $\begin{array}{l}\text { Bosna i Hercegovina, Irska, Kosovo, Makedonija, } \\
\text { Srbija, Švajcarska, Ujedinjeno Kraljevstvo }\end{array}$ & 8 \\
\hline EVROAZIJA & 4 \\
\hline Azerbejdžan, Gruzija, Jermenija, Ukrajina & \\
\hline AZIJA &
\end{tabular}

Bangladeš, Butan, Kambodža, Fidži, Hong Kong, Irak, Jordan, Katar, Malezija, Maldivi, Mjanmar, 16 Pakistan, Palestina, Filipini, Singapur, Šri Lanka

\section{AFRIKA}

Bahrein, Bocvana, Gambija, Gana, Kenija, Lesoto,

Madagaskar, Mauricijus, Nigerija, Siera Leone, Jemen, Južna Afrika, Tanzanija, Saudijska Arabija, Svazilend, Ruanda, Uganda, Ujedinjeni Arapski

Emirati, Zambija, Zimbabve

CENTRALNA I JUŽNA AMERIKA

Argentina, Belize, Bermuda, Brazil, Kostarika, El Salvador, Gvatemala, Honduras, Nikaragva, Panama, Surinam, Čile, Ekvador, Gajana, Peru,

Venecuela, Kolumbija, Urugvaj

KARIBI

Angvila, Antigva i Barbuda, Bahami, Barbados, Dominik, Dominikanska Republika, Grenada, Jamajka, Kajmanaska osrtva, Monserat, Sveti Kits

i Nevis, Sveta Lucija, Sveti Vinsent i Grenadin,

Trinidad i Tobago

UKUPNO

Izvor: IFRS Foundation and The IASB (2016)

Prema zvanično objavljenim podacima Fondacije za MRS, koji su u vreme pripreme ovog rada bili ažurirani 30. avgusta

1 Ovaj rad nema pretenziju da prikaže sve razlike između MSFI za MSP i kompletnih MSFI, već samo one koje su najvažnije. Za potpunu komparativnu analizu ovih razlika pogledati: Grupa autora. (2014). Priručnik za primenu kontnog okvira za srednja, mala i mikropravna lica i preduzetnike u skladu sa MSFI za MSP i Pravilnikom za mikro i druga pravna lica. str. 39-84. Beograd: Privredni savetnik. 
2016. godine, od ukupno 143 jurisdikcije u svetu, 80 zemalja zahteva ili propisuje primenu MSFI za MSP.

Od 80 zemalja, 72 jurisdikcije svojim zakonodavstvom zahteva ili dozvoljava primenu MSFI za MSP bez ikakvih izmena i odstupanja od ovih standarda. Osam zemalja je izvršilo određene modifikacije u verziji MSFI za MSP koja se primenjuje u dotičnoj zemlji u odnosu na zvaničnu verziju ovih standarda. Ovim modifikacijama su dozvoljene alternativne računovodstvene politike procene po fer vrednosti osnovnih sredstava (Irska i Ujedinjeno Kraljevstvo), ne zahteva se sastavljanje izveštaja o tokovima gotovine i izveštaja o promenama na kapitalu (Bosna i Hercegovina), dozvoljena je kapitalizacija troškova pozajmljivanja (Pakistan i Urugvaj) itd.

Od ukupno 80 jurisdikcija samo 8 zemalja su iz Evrope. Ako pogledamo zemlje izvan evropskog kontinenta, vidimo da su MSFI za mala i srednja pravna lica do sada prihvatile siromašne južnoameričke, afričke, azijske zemlje i minijaturne ostrvske zemlje koje nemaju stručne kapacitete i institucije da razviju svoje računovodstvene standarde. Najrazvijenije zemlje sveta (Amerika, Rusija, Kina, Japan, Indija, Turska, zemlje članice EU itd.) nisu prihvatile MSFI za MSP.

\section{STAV EVROPSKE UNIJE PREMA MSFI ZA MSP}

MSFI za MSP su od strane Odbora za MRS utvrđeni u julu 2009. godine i pretrpeli su jedan ciklus izmena i dopuna u maju 2015. godine. Međutim, u prethodnih 7 godina od momenta njihovog usvajanja, EU nije donela nikakvu odluku u vezi sa MSFI za MSP, niti je zauzela bilo kakav zvaničan stav povodom njihovog usvajanja. Umesto toga u junu 2013. EU je usvojila Direktivu EU 2013/34/EU² (u daljem tekstu: nova računovodstvena direktiva EU) koja se primenjuje od 2006. godine u kojoj se ni u jednoj odredbi ne pominju MSFI za MSP. Nova direktiva EU je u većoj meri konervergirala ka MSFI, ali i dalje postoji značajan broj razlika koje su navedene u tački 5 ovog rada.

EU nije izvršila izmenu Uredbe Evropskog parlamenta i Saveta Evropske unije br. 1602/2002 od 19. jula 2002. godine koja se bavi primenom punih MSFI. Naime, prema odredbama ove Uredbe, u zemljama članicama EU od 2005. godine obavezu primene MSFI imaju preduzeća čije se hartije od vrednosti kotiraju na berzi u svojim konsolidovanim finansijskim izveštajima. I Direktivom 2004/109/EC (tzv. Direktiva o transparentnosti) iz 2004. godine propisuje se da su svi izdavaoci hartija od vrednosti, uključujući i one koji su izvan EU, čiji su vrednosni papiri uvršćeni na uređenom tržištu koje se nalazi u EU ili deluju u EU, obavezni da primenjuju MSFI. Ova direktiva ne se odnosi na privredna društva čije se hartije od vrednosti ne nalaze na berzi.

2 Directive 2013/34/EU of the European Parliament and of the Council of 26. june 2013 on the annual financial statements, consolidated financial statements and related reports of certain types of undertakings. Official Journal of the European Union L 182/19 on 29.6.2013.
Što se tiče pojedinačnih finansijskih izveštaja kotirajućih preduzeća i pojedinačnih i konsolidovanih finansijskih izveštaja preduzeća koja se ne kotiraju na berzi, u skladu sa pomenutom Uredbom, svaka država članica EU ima opciju da svojim unutrašnjim zakonodavstvom utvrdi da li će:

1) za pojedinačne finansijske izveštaje kotirajućih preduzeća propisati kao obavezu, dozvoliti kao mogućnost ili zabraniti primenu MSFI;

2) za konsolidovane finansijske izveštaje nekotirajućih preduzeća propisati kao obavezu, dozvoliti kao mogućnost ili zabraniti primenu MSFI, i

3) za pojedinačne finansijske izveštaje nekotirajućih preduzeća propisati kao obavezu, dozvoliti kao mogućnost ili zabraniti primenu MSFI. Uredba EU ne tretira MSFI za MSP jer u vreme njenog donošenja MSFI za MSP nisu ni postojali.

Uredba o primeni MSFI u EU, koja je doneta pre 14 godina, bila je predmet evaluacije 2015. godine povodom desetogodišnjice primene. U izveštaju Evropske komisije Evropskom parlamentu i Savetu o evaluaciji Uredbe 1606/2002 o primeni MRS nisu predviđene ni predložene nikakve izmene postojeće Uredbe. U izveštaju se konstatuje da je istraživanje koje je EK izvršila pokazalo da su „MSFI uspešni u stvaranju jedinstvenog računovodstvenog jezika za tržišta kapitala. Kompanije uglavnom imaju pozitivno iskustvo prilikom korišćenja MSFI i u većini slučajeva koristi nadmašuju troškove. Investitori takođe značajno podržavaju MSFI za unapređenje transparentnosti i uporedivosti finansijskih izveštaja. Većina stejkholdera smatra da proces putem koga MSFI postaju deo prava EU dobro funkcioniše." (European Commision, 2015). Međutim, u izveštaju se ne sugeriše proširenje MSFI na pravna lica koja nisu na berzi, a MSFI za MSP se u izveštaju uopšte ne pominju.

Umesto prihvatanja MSFI za MSP u EU je od strane Evropskog parlamenta i Saveta 26. juna 2013. godine usvojena nova računovodstena Direktiva EU 2013/34/EU sa kojom su države članice trebale da usaglase svoja nacionalna zakonodavstva do 20. juna 2015. godine. Nova direktiva primenjuje se na finansijske izveštaje od 2016. godine.

U Evropi, koja nas prevashodno interesuje, MSFI za MSP se, sem u Srbiji, primenjuju samo u Bosni i Hercegovini, Makedoniji, Švajcarskoj, Ujedinjenom Kraljevstvu i Irskoj (kao i na Kosovu). U svim ostalim evropskim zemljama ne primenjuju se MSFI za MSP, već nacionalni računovodstveni propisi bazirani na novoj direktivi EU.

Pošto Makedonija, Bosna i Hercegovina i Švajcarska nisu članice EU, od zemalja članica jedino su Ujedinjeno Kraljevstvo i Irska prihvatile MSFI za MSP i to ne u originalnom obliku. Ujedinjeno Kraljevstvo i Irska dozvolile su alternativne računovodstvene politike koje nisu moguće po MSFI za MSP (procena po fer vrednosti osnovnih sredstava, mogućnost kapitalizacije ulaganja i razvoj i troškova pozajmljivanja). Za Ujedinjeno Kraljevstvo i Irsku posebno treba napomenuti da 
nisu direktno usvojile MSFI za MSP, već su donele svoje nacionalne računovodstvene standarde bazirane na MSFI za MSP. U Velikoj Britaniji i Irskoj Savet za nacionalno izveštavanje usvojio je u martu 2013. standard FRS 102 Standard finansijskog izveštavanja primenjiv u UK i Irskoj koji se primenjuje od 1. januara 2015. godine i koji je baziran na MSFI za MSP, ali sa navedenim razlikama u odnosu na zvanične MSFI za MSP.

Nijedna od ostalih 26 zemalja članica EU nije propisala niti dozvolila sastavljanje finansijskih izveštaja prema MSFI za MSP.

Na zvaničnom sajtu Odbora za MRS u delu posvećenom profilu za EU navodi se „da je ocenjeno da su MSFI za MSP nekompatibilni sa računovodstvenom direktivom EU. Kao rezultat toga, MSFI za MSP nisu odobreni u EU.“ (IFRS Foundation and The IASB, 2016)

Na osnovu iznetog možemo zaključiti da MSFI za MSP nisu deo pravne tekovine EU i nije izvesno da li će i kada će to postati.

\section{RAZLIKE IZMEĐU MSFI ZA MSP I NOVE RAČUNOVODSTVENE DIREKTIVE EU}

Jedan od važnih principa, koji je istaknut u preambuli nove direktive, je da računovodstveno izveštavanje Unije treba da uspostavi odgovarajuću ravnotežu između interesa korisnika finansijkih izveštaja i interesa preduzeća tako da preduzeća ne budu nepotrebno opterećena obavezom izveštavanja. Zbog postignutog koncenzusa da su stare računovodstvene direktive često bile opterećujuće za mala i srednja pravna lica, a posebno za mikro poslovne subjekte, izvršena je njihova detaljna revizija i umesto ranije dve (Četvrta direktiva EU 78/660/EEZ iz 1978. godine i Sedma direktiva EU 83/349/ EEZ iz 1983. godine) usvojena je nova računovodstvena direktiva EU koja pokriva područja godišnjih i konsolidovanih finansijskih izveštaja i revizije.

Novom računovodstvenom direktivom EU iz juna 2013. godine nisu prihvaćeni MSFI za MSP. Prema javno dostupnim dokumentima i materijalima relevantnih evropskih institucija nije moguće utvrditi da li će ih EU prihvatiti u bliskoj budućnosti.

U analizi razlika između MSFI za MSP i starih računovodstvenih direktiva (Četvrte i Sedme) koju je u maju 2010. izvršio EFRAG (European Financial Reporting Advisory Gro$u p)$ - Evropska savetodavna grupa za finansijsko izveštavanje, konstatovan je značajan broj razlika između ova dva računovodstvena okvira koje se tiču: prikazivanja vanrednih dobitaka i gubitaka; procenjivanja finansijskih instrumenata po fer vrednosti; amortizacije gudvila u roku od 10 godina, kada pouzdana procena veka trajanja nije moguća; priznavanja negativnog gudvila u bilansu uspeha kao prihoda; prikazivanja upisanog, a neuplaćenog kapitala kao odbitne stavke kapitala; i storniranja gubitka zbog umanjenja vrednosti gudvila (European Financial Reporting Advisory Group, 2010). Budući da je od 2016. godine u primeni nova računovodstvena direktiva EU, kao i zbog izmena samih MSFI za MSP, analiza razlika koju je izvršio EFRAG više nije aktuelna, ali se može primetiti da su u novoj direktivi otklonjene razlike koje su ranije postojale. Jedina stara razlika koja je ostala tiče se prikazivanja upisanog, a neuplaćenog kapitala. Međutim, pojavile su se nove razlike koje prikazujemo u nastavku.

Zbog nedostatka novijih analiza neusaklađenosti između MSFI za MSP i nove EU računovodstvene direktive drugih profesionalnih i zvaničnih evropskih organizacija i tela, autor je izvršio samostalno poređenje i utvrdio da se izdvajaju sledeće razlike:

- Godišnji finansijski izveštaj malih pravnih lica. Nova direktiva EU (čl. 4) predviđa da godišnji finansijski izveštaj obuhvata najmanje bilans stanja, bilans uspeha i napomene uz finansijske izveštaje. Država članica može zahtevati od preduzeća, osim malih preduzeća, sastavljanje drugih finansijskih izveštaja, pored navedenih. Takođe, država članica može zahtevati od preduzeća, osim malih preduzeća, da u godišnjem finansijskom izveštaju objavljuju i dodatne informacije, pored onih koje se moraju objavljivati u skladu sa ovom direktivom. Za mala pravna lica država članica može propisati obelodanjivanje dodatnih informacija izričito za potrebe naplate poreza, ukoliko je zahtev za tim sadržan u nacionalnom poreskom zakonodavstvu. Direktiva propisuje da država članica koja koristi elektronska rešenja za registraciju i objavljivanje finansijskih izveštaja (što je slučaj sa Srbijom) treba da obezbedi da mala pravna lica nisu dužna da obelodanjuju dodatne informacije za poreske svrhe u prethodnonavedenom smislu.

Nasuprot direktivi EU MSFI za MSP u Odeljku 3 - Prezentacija finansijskih izveštaja (par. 3.17) propisuje da potpun set finansijskih izveštaja podrazumeva obavezu sastavljanja izveštaja o tokovima gotovine, izveštaja o promenama na kapitalu i izveštaja o ostalom ukupnom rezultatu.

- Prikazivanje upisanog-neupisanog kapitala. MSFI za MSP u Odeljku 22 - Obaveze i kapital (par. 22.7) propisuje da ako se instrumenti kapitala izdaju pre nego što subjekt primi novac ili druge resurse, subjekt iznos potraživanja treba da prikaže kao odbitnu stavku kapitala u izveštaju o finansisjkom položaju, a ne kao imovinu. Nova direktiva EU, u prilozima III i IV koji predstavljaju alternativne obrasce bilansa stanja, predviđa posebne bilansne pozicije u aktivi i kapitalu za upisani, a neuplaćeni kapital.

- Procena nekretnina, postrojenja i opreme po fer vrednosti. Dok je stara verzija MSFI za MSP u Odeljku 17 - Nekretnine, postrojenja i oprema (par. 17.15) zabranjivala procenjivanje nematerijalnih ulaganja, nekret- 
nina, postrojenja i opreme po fer vrednosti, direktiva EU u čl. 8, dozvoljava državama članicama da omoguće računovodstveno iskazivanje osnovnih sredstava po fer vrednosti.

Ova neusaglašenost je otklonjena u „novoj“ verziji MSFI za MSP, koja je usvojena u maju 2015. godine, a koja stupa na snagu 01.01.2017. Međutim, izmene Odeljka 17 MSFI za MSP kojima je dozvoljena procena po fer vrednosti nekretnina, postrojenja i oprema nisu objavljene u Službenom glasniku RS, što je preduslov za njihovu primenu, te se još ne mogu primenjivati.

- Kapitalizacija kamate i drugih troškova pozajmljivanja. MSFI za MSP u Odeljku 25 - Troškovi pozajmljivanja (par. 25.2) propisuje da se svi troškovi pozajmljivanja priznaju kao rashod u bilansu uspeha, za period u kojem su nastali. Nasuprot tome, direktiva EU sadrži odredbu da država članica može dozvoliti ili zahtevati da se kamata na pozajmljeni kapital, radi finansiranja proizvodnje dugoročne ili tekuće imovine, uključi u troškove proizvodnje u onoj meri u kojoj se ona odnosi na period proizvodnje, i da primenu ove odredbe treba navesti u napomenama uz finanijske izveštaje.

- Ulaganja u razvoj i troškovi osnivanja. MSFI za MSP u Odeljku 18 - Nematerijalna imovina osim gudvila (par. 18.14 i 18.15) zabranjuju kapitalizaciju ulaganja u razvoj i troškove osnivanja, nalažući njihovo obavezno evidentiranje na teret rashoda perioda u kojem nastanu. Nova direktiva EU u čl. 12.11 dozvoljava kapitalizaciju troškova razvoja i troškova osnivanja pod uslovom da je to predviđeno nacionalnim pravom. U slučaju da država članica nacionalnim pravom da mogućnost iskazivanja ulaganja u razvoj kao nematerijalnih ulaganja direktiva predviđa da država članica može ograničiti raspodelu dobiti preduzeća, osim ako je iznos neraspoređene dobiti i iznos raspoloživih rezervi za raspodelu najmanje jednak iznosu neotpisanih troškova razvoja, i da se otpis vrši u periodu koji ne može biti kraći od 5 , niti duži od 10 godina. U slučaju da država članica, svojim nacionalnim pravom, dozvoli iskazivanje troškova osnivanja kao nematerijalnih troškova, oni se prema direktivi moraju otpisati u roku od najviše 5 godina. Obe šeme bilansa stanja (horizontalna i vertikalna), koje su date u prilogu direktive, sadrže posebne bilansne pozicije za kapitalizovane troškove razvoja i troškove osnivanja.

- Amortizacija gudvila. MSFI za MSP (Odeljak 19 Poslovna spajanja i gudvil) i Direktiva EU predviđaju obavezu amortizacije i obezvređenja gudvila u skladu sa procenjenim vekom trajanja koji ne može biti duži od 10 godina, s tom razlikom da MSFI za MSP ne postavljaju najkraći period amortizacije, dok Direktiva u čl. 12.11 propisuje da period amortizacije gudvila ne može biti kraći od 5 godina.
- Vrednovanje učešća u zavisnim, pridruženim i zajednički kontrolisanim pravnim licima. MSFI za MSP u Odeljku 9 - Konsolidovani i pojedinačni finansijski izveštaji (par 9.26) propisuje da u svojim pojedinačnim finansijskim izveštajima pravno lice koje ima učešće u zavisnom, pridruženom ili zajednički kontrolisanom pravnom licu treba da iskaže po jednoj od tri ponuđene računovodstvene politike:

(a) po nabavnoj vrednosti umanjenoj za umanjenje vrednosti,

(b) po fer vrednosti sa promenama fer vrednosti iskazanim kao dobitak ili gubitak u bilansu uspeha ili (c) koristeći metodu udela.

Nasuprot MSFI za MSP, koji dozvoljavaju procenjivanje učešća po fer vrednosti ili po metodi udela, Direktiva EU u čl. 6.1(i) i čl. 8.4(c) zabranjuje vrednovanje po fer vrednosti i zahteva da se u pojedinačnim finansijskim izveštajima ulagača vrednovanje vrši po principu nabavne vrednosti.

- LIFO metoda obračuna izlaza zaliha. MSFI za MSP (Odeljak 13 - Zalihe) zabranjuje primenu LIFO metode, dok Direktiva EU u čl. 12.9 daje pravo državi članici da osim metode specifične identifikacije, metode ponderisane prosečne cene i FIFO metode, dozvoli i primenu LIFO metode ili bilo koje druge metode koja odražava uopšteno prihvaćenu najbolju praksu.

- Izveštaj o ostalom ukupnom rezultatu, izveštaj o promenama na kapitalu i izveštaj o tokovima gotovine. Prema MSFI za MSP (Odeljak 3 - Prezentacija finansijkih izveštaja) kompletan set finansijskih izveštaja sadrži i izveštaj o ostalom (sveobuhvatnom) ukupnom rezultatu, izveštaj o promenama na kapitalu i izveštaj o tokovima gotovine. Izveštaj o ostalom ukupnom rezultatu može se prezentovati kao poseban segment bilansa uspeha ili kao poseban izveštaj odvojen od bilansa uspeha. U Srbiji se sastavlja kao poseban izveštaj odvojen od bilansa uspeha. Direktiva EU ne pominje ove finansijske izveštaje, ali daje pravo državama članicama da ih uvedu za svoja pravna lica, sa izuzetkom malih i mikro pravnih lica. U našoj zemlji mikropravna lica ne moraju da sastavljaju ove izveštaje, ali mala pravna lica imaju tu obavezu.

- Izuzeće od obaveze sastavljanja konsolidovanih finansijskih izveštaja. Nova direktiva EU u čl. 23. predviđa izuzeće od obaveze sastavljanja konsolidovanih finansijskih izveštaja za male grupe povezanih pravnih lica, osim ako je neko od povezanih subjekata unutar grupe subjekt od javnog interesa. Mala grupa je grupa sastavljena od matičnog i zavisnih pravnih lica, koja po dva od tri kriterijuma ne prelazi sledeće granične vrednosti:

(a) zbir bilansa stanja do 4.000.000 EUR,

(b) poslovni prihod manji od 8.000.000 EUR,

(c) prosečan broj zaposlenih manji od 50 . 
Direktiva državama članicama daje pravo da od obaveze konsolidacije izuzmu i srednje grupe povezanih pravnih lica, osim ako je neko od povezanih subjekata unutar grupe subjekt od javnog interesa. Takođe, direktiva predviđa da se matično pravno lice koje je ujedno zavisno pravno lice, uključujući i subjekt od javnog interesa, izuzme od konsolidacije finansijskih izveštaja, ako njegovo matično pravno lice drži sve ili najmanje 90\% akcija/udela izuzetog matičnog preduzeća, ili ako $90 \%$ konsolidacija vrši drugo matično društvo na višem nivou.

MSFI za MSP u Odeljku 9 (par 9.3) predviđa izuzetke od prezentovanja konsolidovanih finansijskih izveštaja, ako je matični entitet zavisni entitet i krajnji matični entitet sastavlja konsolidovane finansijske izveštaje u skladu sa punim MSFI ili MSFI za MSP, ali ne predviđa izuzeće od konsolidacije za grupe povezanih pravnih lica male ili srednje veličine.

Zakon o računovodstvu Republike Srbije predviđa izuzeće od konsolidacije, kada je matično pravno lice istovremeno zavisno društvo drugog domaćeg pravnog lica ili je grupa ispod polovine graničnih iznosa za malo pravno lice, ali su granični iznosi u Zakonu u nesaglasju sa kriterijumima iz direktive. Naime, prema direktivi, jedan od kriterijuma za utvrđivanje veličine grupe je i broj zaposlenih, što Zakon nije predvideo. Osim toga, polovina graničnih iznosa za malo pravno lice po Zakonu o računovodstvu iznosi: za poslovni prihod (4.400.000 EUR, a prosečna vrednost poslovne imovine 2.200.000 EUR). Kako je ranije istaknuto, ove veličine su: poslovni prihod manji od 8.000 .000 EUR, a prosečna vrednost poslovne imovine manja od 4.000.000 EUR.

- Metoda propocionalne konsolidacije. Direktiva EU u čl. 26. daje državi članici pravo da dozvoli da se u krug konsolidovanja uključe i zajednički kontrolisana pravna lica i da se konsolidacija istih vrši metodom proporcionalne konsolidacije. MSFI za MSP (uostalom, kao i kompletni MSFI) ne dozvoljavaju metodu proporcionalne konsolidacije za zajednički kontrolisana pravna lica.

\section{IZVEŠTAJ SVETSKE BANKE O POŠTOVANJU PROPISA I STANDARDA IZ OBLASTI RAČUNOVODSTVA ZA SRBIJU ZA 2015. GODINU (ROSC SRBIJA)}

Zanimljivo je osvrnuti se i na izveštaj Svetske banke o poštovanju propisa i standarda iz oblasti računovodstva (u daljem tekstu: ROSC Srbija) koji je publikovan u junu 2015. godine. U ovom izveštaju zapaža se značajan napredak u reformi računovodstvenih propisa koji je ostvaren aktuelnim
Zakonom o računovodstvu i Zakonom o reviziji, koje je Srbija usvojila u julu 2013. u odnosu na 2005. godinu, kada je vršeno prethodno ispitivanje, ali se uočavaju i određeni nedostaci i daju preporuke za njihovo otklanjanje. Ovde obrađujemo samo deo izveštaja koji se odnosi na primenu MSFI za MSP u Srbiji.

Tako Svetska banka u ROSC Srbija za 2015. godinu konstatuje da ,tekući zahtevi u vezi sa primenom MSFI za MSP predstavljaju teret i nerealni su za mala pravna lica. Slično tome, Srbija može razmotriti da li su zahtevi da sva velika pravna lica primenjuju pune MSFI postavljeni suviše široko, i da li sužavanje ovih zahteva može obezbediti realističnije i jeftinije usaglašavanje, koje će istovremeno obezbediti adekvatne informacije za korisnike njihovih finansijskih izveštaja" (Center for the Financial Reporting Reform, 2015: str. vii, 43).

U delu izveštaja o područjima za dalje razmatranje Svetska banka predlaže da se u pravnom okviru za korporativno finansijsko izveštajanje izvrši ,ponovno razmatranje zahteva da mala pravna lica primenjuju MSFI za MSP i posebno zahtevi da sva velika pravna lica primenjuju pune MSFI“ (Center for the Financial Reporting Reform, 2015: str. v).

Prema ocenama Svetske banke korporativno finansijsko izveštavanje u Srbiji je poslednjih godina znatno unapređeno, ali i dalje nije u potpunoj saglasnosti sa praksama i standardima Evropske unije. Činjenica je da je Zakon o računovodstvu iz jula 2013. godine značajno harmonizovao srpsko pravo u oblasti korporativnog računovodstva sa pravnim tekovinama $\mathrm{EU}$, ali ostale su neusaglašenosti i stoga , je potrebno smanjiti broj velikih pravnih lica koja primenjuju pune MSFI i povećati broj malih pravnih lica sa opcijom da primenjuju MSFI za MSP putem povećanja graničnih iznosa sa razvrstavanje“ (Center for the Financial Reporting Reform, 2015: str. 8).

Opšta ocena, koja se u izveštaju pojavljuje na više mesta, je da je reforma Zakona o računovodstvu i Zakona o reviziji izvršena u skladu sa Četvrtom i Sedmom direktivom EU, koje su zamenjene novom direktivom EU, pa je potrebna izmena ovih propisa u cilju usaglašavanja sa novom direktivom. Inače, kao zemlja kandidat za EU, naša zemlja ima rok do kraja 2018. godine da izvrši usaglašavanje sa novom računovodstvenom direktivom EU.

\section{NEPOVOLJNE POSLEDICE PRIMENE MSFI ZA MSP NA MALA PRAVNA LICA I UTICAJ NA RIZIKE POSLOVANJA}

Osim neuglašenosti postojećeg okvira za finansijsko izveštavanje malih i srednjih pravnih lica sa pravnim tekovinama EU (što smo maločas prikazali), MSFI za MSP ostavljaju i niz negativnih posledica po same privredne subjekte koji ih primenjuju. Te negativne posledice posebno dolaze do izražaja kod malih pravnih lica koja nemaju mogućnost dobrovoljne primene kompletnih MSFI, a manje se ispoljavaju kod sred- 
njih pravnih lica koja mogu da izaberu između MSFI za MSP i punih MSFI.

Prilikom sastavljanja finansijskih izveštaja za 2014. i 2015. godinu, posebno su se ispoljile sledeće negativne posledice primene MSFI za MSP na mala pravna lica:

Veće administrativno opterećenje i uvećani troškovi pripreme finansijskih izveštaja bez vidljivijih koristi za bilansne adresate. Do 2013. godine mala pravna lica su, u skladu sa tada važećim propisima iz oblasti računovodstva, od finansijskih izveštaja dostavljala bilans stanja, bilans uspeha i statistički aneks. Mala pravna lica nisu morala da vrše iskazivanje odloženih poreskih sredstava i obaveza; da vrše ukalkulisavanje rezervisanja za otpremnine prilikom odlaska u penziju i druge naknade koje se isplaćuju zaposlenima; nisu morala da predaju izveštaj o tokovima gotovine i izveštaj o promenama na kapitalu; sastavljaju napomene uz finansijske izveštaje i sl.

Međutim, počevši od 2014. godine mala pravna lica moraju da predaju kompletan set finansijskih izveštaja, dužna su da obračunavaju odložene poreze po osnovu privremenih razlika između poslovne i oporezive dobiti; treba da obračunavaju i rezervisanja prilikom odlaska u penziju i ostale naknade koje se isplaćuju zaposlenima itd. MSFI za MSP malim pravnim licima nameću niz novih obračunskih obaveza, što za njih predstavlja značajno administrativno opterećenje i povećava vreme i troškove oko sastavljanja finansijskih izveštaja, a bez značajnijeg unapređenja kvaliteta finansijskih izveštaja. Troškovi obezbeđivanja ovih informacija, koji padaju na teret pravnog lica, su značajni (naročito kod rezervisanja za otpremine prilikom odlaska u penziju čije procenjivanje zahteva značajno profesionalno prosuđivanje i korišćenje aktuarskih obračuna), a koristi od njih koje ostvaruju korisnici finansijskih informacija su zanemarljive. Ovo treba staviti pod lupu principa ekonomičnosti, koji se zalaže za ravnotežu između troškova i koristi. Navedene dodatne obračunske obaveze nisu predviđene novom računovodstvenom direktivom EU čiji je cilj smanjenje nepotrebne birokratije za mikro i mala pravna lica.

Uvećanje poreskih obaveza na ime poreza na imovinu na nepokretnosti u statici. Zakon o porezima na imovinu i propisi koji su na osnovu njega doneti su predvideli da je osnovica poreza na imovinu u statici na nepokretnosti, po stopi od $0,4 \%$ za obveznika koji vodi knjige, vrednost koja se dobija množenjem korisne površine i prosečne cene kvadratnog metra odgovarajuće nepokretnosti u zoni u kojoj se nalazi nepokretnost, koju utvrđuje svaka jedinica lokalne samouprave. Umesto na ovaj način, obveznici koji vode poslovne knjige mogu osnovicu poreza na imovinu na nepokretnosti utvrditi u visini fer vrednosti na poslednji dan tekuće poslovne godine u skladu sa MRS, odnosno MSFI i usvojenim računovodstvenim politikama.

Pravna lica koja primenjuju kompletne MSFI mogu, kao osnovicu poreza na imovinu, da uzmu procenjenu fer vrednost, pod uslovom da su računovodstvenim politikama za bilansiranje nekretnina izabrali model fer vrednosti. Ovu mogućnost, koja je uvedena od 2014. godine, iskoristio je veliki broj pravnih lica koja primenjuju MSFI, iz razloga što je tako utvrđena poreska osnovica znatno niža nego kada se utvrđuje na bazi prosečne cene nepokretnosti koju utvrđuje lokalna samouprava.

Na drugoj strani, pravna lica koja primenjuju MSFI za MSP ne mogu kao osnovicu poreza na imovinu za nepokretnosti za obavljanje delatnosti da uzmu procenjenu fer vrednost, jer MSFI za MSP i Pravilnik za mikropravna lica zabranjuju revalorizaciju nekretnina, postrojenja i opreme za obavljanje delatnosti. U međuvremenu, usvojeni su amandmani na MSFI za MSP kojima je dozvoljeno procenjivanje osnovnih sredstava po fer vrednosti, ali još uvek nisu objavljene u Službenom glasniku RS, te se ne mogu primenjivati.

MSFI za MSP i Pravilnik za mikropravna lica nalažu da se vrednovanje investicionih nekretnina vrši po fer vrednosti preko bilansa uspeha. Međutim, mikro i mala pravna lica ne mogu da uzmu procenjenu fer vrednost za investicione nepokretnosti, budući da se u čl. 7 Zakona o porezima na imovinu pominju MRS i MSFI, a ne pominju se MSFI za MSP.

Mikro i mala pravna lica će fer vrednost moći da koriste kao osnovicu poreza na imovinu, tek kada se u Službenom glasniku RS objave usvojene izmene i dopune MSFI, i shodno njima izvrše izmene Pravilnika za mikropravna lica, i kada se odredba čl. 7. Zakona o porezima na imovinu dopuni dodavanjem ovih propisa.

Iskazivanje većih rashoda i lošijeg finansijskog rezultata. Privredni subjekti koji primenjuju MSFI za MSP, kao i mikropravna lica koja primenjuju Pravilnik za mikro pravna lica, u cenu koštanja ne mogu uključiti troškove kamata i ostale troškove pozajmljivanja za sticanje, nabavku ili izgradnju sredstva koja se osposobljavaju za upotrebu, odnosno vrednost sredstva, budući da MSFI za MSP zabranjuju kapitalizaciju ovih finansijskih rashoda.

Primera radi, pravno lice koje primenjuje kompletne MSFI troškove kamate za finansiranje izgradnje objekta čija izgradnja još nije završena, u iznosu od 250.000 EUR, neće iskazati kao rashod u godini na koju se obračun odnosi, već će trošak kamate od 250.000 EUR uključiti u vrednost objekta i iskazati ga na računu 026 - Nekretnine, postrojenja i oprema u pripremi, a na rashode će biti preneti kada objekat bude priveden nameni i počne da se koristi, i to putem amortizacije u skladu sa procenjenim vekom trajanja. Za razliku od ovog ekonomskog entiteta, mikro ili malo pravno lice koje primenjuje MSFI za MSP mora celokupan iznos od 250.000 EUR da iskaže kao finansijski rashod u godini na koju se trošak kamate odnosi, zaduženjem računa 562 - Rashodi kamata. $\mathrm{Na}$ ovaj način, mikro ili malo pravno lice je dovedeno u diskriminatorni položaj u odnosu na pravno lice koje primenjuje kompletne MSFI, jer istu transakciju knjiži na drugačiji način i kao posledicu toga u ovoj godini iskazuje veće troškove i manju dobit. 
Takođe, kod ulaganja u razvoj novih proizvoda, tehnologija, proizvodnih procesa i sl. puni MSFI propisuju da se troškovi istraživanja priznaju kao tekući rashod, a da se troškovi razvoja priznaju kao nematerijalno ulaganje i amortizuju u procenjenom veku trajanja, dok MSFI za MSP i Pravilnik za mikropravna lica nalažu da se svi troškovi istraživanja i razvoja imaju iskazati kao rashod perioda u kome su nastali. Ovo stvara značajne probleme mikro i malim pravnim licima koja imaju velike izdatke u nove razvojne projekte, što je u našoj zemlji karakteristično za start-up firme i IT sektor čije kompanije ulažu resurse u razvoj novih softverskih rešenja, aplikacija i informacionih platformi. Primera radi, softverska kompanija A, koja primenjuje kompletne MSFI, će ulaganja u razvoj novih aplikacija u iznosu od 400.000 EUR iskazati kao nematerijalno ulaganje preko računa 010 - Ulaganja i razvoj, i putem amortizacije će izvršena ulaganja sistematski raspodeliti na više obračunskih perioda. Softverska kompanija B - mikro ili malo pravno lice će celokupan iznos od 400.00 EUR morati da iskaže kao rashod godine u kojoj su nastali i knjiži ih preko računa 537 - Troškovi razvoja koji se ne kapitalizuju, što dovodi pravno lice B u diskriminatorni položaj u odnosu na pravno lice $\mathrm{A}$, samo zbog činjenice da pravno lice B primenjuje MSFI za MSP ili Pravilnik za mikropravna lica.

U revidiranoj verziji MSFI za MSP iz maja 2015. godine, koja stupa na snagu počev od 1. januara 2017. godine, nisu izvršene izmene po ovom pitanju, te i dalje postoji zabrana kapitalizacije troškova kamata i ulaganja u razvoj, što će nastaviti da predstavlja problem za mala pravna lica koja primenjuju MSFI za MSP i za mikropravna lica koja primenjuju Pravilnik za mikropravna lica.

Poznato je da mala i mikropravna lica imaju otežan pristup tržištu novca i kapitala. Iskazujući manju profitabilnost, zbog računovodstvene regulative koju primenjuju, mala i mikropravna lica pribavljaju kapital od banaka i ostalih poverilaca pod nepovoljnijim uslovima. Ovim mehanizmom MSFI za MSP povećavaju kreditni rizik i rizik od kreativnog računovodstva. Sem toga, MSFI za MSP se menjaju svake godine što povećava rizik od pogrešnih tumačenja i pogrešne primene sa svim negativnim posledicama koje iz toga proizilaze.

\section{ZAKLJUČAK}

Glavne kontroverze u vezi sa primenom MSFI za MSP su u tome što je Srbija izvršila njihovo preuranjeno prihvatanje, imajući u vidu strukturu zemalja koje su do sada propisale njihovu primenu (siromašne afričke, azijske, južnoameričke zemlje i minijaturne ostrvske države). MSFI za MSP trenutno nisu deo pravne tekovine Evropske unije i nije izvesno da li će i kada to postati. Umesto prihvatanja MSFI za MSP u junu 2013. godine, EU je usvojila novu računovodstvenu direktivu sa kojom su zemlje članice usaglasile svoje nacionalne računovodstvene propise i standarde do 20. juna 2015. godine i koja se primenjuje na finansijske izveštaje od 2016. godine.
Iako je nova EU računovodstvena direktiva konvergirala ka MSFI za MSP u većoj meri nego prethodne direktive, i dalje postoje značajna razlike između ove direktive i MSFI za MSP koji se odnose na set finansijskih izveštaja za mala pravna lica, kapitalizaciju kamate, troškova razvoja i osnivačkih troškova, amortizaciju gudvila, vrednovanje učešća u zavisnim, pridruženim i zajednički kontrolisanim pravnim licima u pojedinačnim finansijskim izveštajima ulagača, izuzeće od obaveze konsolidovanja finansijskih izveštaja, metodu proporcionalne konsolidacije, prikazivanje upisanog i neuplaćenog kapitala, LIFO metodu obračuna izlaza zaliha.

Republika Srbija dužna je da do kraja 2018. godine uskladi svoje računovodstvene propise sa zahtevima nove Direktive što podrazumeva i preispitivanje odnosa prema direktnom prihvatanju MSFI za MSP.

Primenom MSFI za MSP posebno su pogođena mala pravna lica koja imaju dodatne obračunske obaveze i znatno veće troškove pripreme finansijskih izveštaja. Zabrana procenjivanja osnovnih sredstava po fer vrednosti i zabrana kapitalizacije troškova pozajmljivanja i ulaganja u razvoj MSFI za MSP nepovoljno deluju na uvećanje obaveza na ime poreza na imovinu u statici, te na pogoršavanje njihove zarađivačke sposobnosti, što povećava kreditni rizik i opasnosti od kreativnog računovodstva.

Jedna od preporuka Svetske banke u Izveštaju o poštovanju propisa iz oblasti računovodstva iz juna 2015. godine tiče se potrebe da Srbija ponovo razmotri zahtev da mala pravna lica primenjuju MSFI za MSP.

\section{LITERATURA}

Center for the Financial Reporting Reform. (2015). Report on the Observance of Standards and Codes on Accounting and Auditing - Republic of Serbia. Vienna, Austria: World Bank.

EUR-Lex. (2013). Directive 2013/34/EU of the European Parliament and of the Council of 26. June 2013 on the annual financial statements, consolidated financial statements and related reports of certain types of undertakings.

Retrieved September 9, 2016 from http://eur-lex.europa.eu/ legal-content/EN/TXT/?uri=CELEX\%3A32013L0034 European Commision. (2015). Report from the Commission to the European Parliament and the Concil - Evaluation of Regulation (EC) NO 1606/2002 of 19 July 2002 on the application of International Accounting Standards. Retrieved September 9, 2016 from http://ec.europa.eu/finance/company-reporting/ias-evaluation/index_en.htm.

European Financial Reporting Advisory Group. (2010). Advice on compatibility of the IFRS for SMEs and the EU Accounting Directives. Retrieved September 9, 2016 from http://www. efrag.org/.

Grupa autora. (2014). Priručnik za primenu kontnog okvira za srednja, mala i mikropravna lica i preduzetnike u skladu sa MSFI za MSP i Pravilnikom za mikro i druga pravna lica. Beograd: Privredni savetnik. 
IFRS Foundation and the IASB. (2015). 2015 Amendments to the IFRS for SMEs. Retrieved September 8, 2016 from http:// eifrs.ifrs.org/eifrs/Menu.

IFRS Foundation and the IASB. (2016). Analysis of the IFRS profiles for the IFRS for SMEs Standard. Retrieved September 12, 2016 from http://www.ifrs.org/Use-around-the-world/ Pages/Analysis-of-SME-profiles.aspx.

IFRS Foundation and the IASB. (2016). IFRS Application around the world - Jurisdictional Profile: Europe Union. Retrieved September 9, 2016 from http://www.ifrs.org/Use-aroundthe-world/Documents/Jurisdiction-profiles/European-Union-IFRS-Profile.pdf.
Ministarstvo finansija Republike Srbije. (2013). Rešenje o utvrđivanju prevoda Međunarodnog stanarda finansijskog izveštavanja za mala i srednja pravna lica MSFI za MS. Retrieved September 9, 2016 from http://www.mfin.gov.rs/pages/issue. php?id $=6541$

Službeni glasnik RS. (2013). Zakon o računovodstvu. Službeni glasnik RS br. 62/2013

\section{CONTROVERSY REGARDING THE APPLICATION OF IFRS FOR SMALL AND MEDIUM-SIZED ENTITIES IN SERBIA}

\section{Abstract:}

In this paper we examine the challenges and difficulties in the practical application of the International Financial Reporting Standards for small and medium-sized entities (IFRS for SMEs) and review the adequacy and appropriateness of their application in the Republic of Serbia.

By comparing with full International Financial Reporting Standards, the paper presents the specific features of IFRS for small and medium-sized entities, analyzes the differences between IFRS for SMEs and the EU Accounting Directive 2013/34/EU of the European Parliament and of the Council of 26 June 2013, and shows the degree of application of IFRS for small and medium-sized entities in the European Union and other countries outside the EU.

In addition, it was pointed out how the application of IFRS for SMEs leading small and mediumsized entities in a discriminatory situation in relation to the companies who apply full IFRS and the unnecessary complication of the accounting regulations for the preparation of financial statements. The paper also considers other issues related to the implementation of IFRS for SMEs that particularly relates to small companies, which are manifested in two years of application of the professional accounting standards in Serbia, ie. the preparation of financial statements for 2014 and 2015.

\section{Keywords:}

small and medium-sized entities, IFRS for small and medium-sized entities (IFRS for SMEs), International Financial Reporting Standards (IFRS),

Accounting Directive of the European Union, accounting policies. 